\title{
Advance Care Planning During the COVID-19 Pandemic
}

\author{
Melissa A. Bender, MD, FAAHPM, Kuang-Ning Huang, MD, MPH, and \\ Jaqueline Raetz, $M D$
}

Advance care planning (ACP) is especially important during the COVID-19 pandemic. Previously identified barriers to ACP include lack of time during patient visits, billing, clinician and patient discomfort and lack of resources, and difficulties with documenting and accessing ACP documents. Here we describe new challenges and new opportunities for ACP that have arisen from the COVID-19 pandemic, both due to the complexities of the illness and expedited changes in some of the stagnancies in the health care system. The shared risk for COVID-19 that all people face brings urgency to institutional policy changes to ACP form completion. However, research should assess acceptability and effectiveness of these strategies. ( $\mathrm{J}$ Am Board Fam Med 2021;34:S16-S20.)

Keywords: Advance Care Planning, CoVID-19, Critical Illness, Delivery of Health Care, Health Resources, Organizational Policy, Pandemics, Patient Preference, Telemedicine

\section{Introduction}

Two men in their 20s with COVID-19 declined their legal next of kin as surrogate decision maker. The restriction on hospital visitors made impossible the usual process of notarizing durable power of attorney for health care (DPOA-HC) forms. An emergency institutional policy change and the creative idea of using carbon copy paper allowed both patients to complete DPOA-HC forms before being intubated.

Advance care planning (ACP) conversations, including designating a DPOA-HC, are ideally done in nonemergent situations using a shared decisionmaking approach. ${ }^{1}$ If a patient has new or advancing illness later, his or her wishes can then be confirmed or readdressed. Previously identified barriers to this process include lack of time during patient visits, billing, clinician and patient discomfort and lack of resources, and difficulties with documenting and accessing ACP documents. ${ }^{2-9}$ New challenges and

This article was externally peer reviewed.

Submitted 16 May 2020; revised 14 July 2020; accepted 20 July 2020.

From the University of Washington School of Medicine, Department of Family Medicine.

Funding: None.

Conflict of interests: None.

Corresponding author: Melissa A. Bender, MD, FAAHPM, Department of Family Medicine, University of Washington School of Medicine, 1959 NE Pacific St, Seattle, WA 98195 (E-mail: benderma@uw.edu). new opportunities for ACP have arisen from the COVID-19 pandemic, both due to the complexities of the illness and expedited changes in some of the stagnancies in the health care system.

\section{The COVID-19 Pandemic Heightens the Urgency for Having ACP Conversations}

The shared risk for COVID-19 that all people face, new increases in cases across the United States, and the possibility of rapid decline like the 2 men experienced bring urgency to ACP conversations in patients who are hospitalized or in the outpatient setting with COVID-19 or unrelated diagnoses. ACP experts recommend that all adults designate a health care surrogate decision maker and complete an advance directive form. ${ }^{9,10}$ Clinicians may choose to base having ACP conversations on prognosis due to time constraints. ${ }^{11}$ Given the high morbidity and mortality, potential for rapid decline, and many uncertainties associated with COVID-19 illness, it would be beneficial to encourage all adult patients to discuss and document their wishes for their medical care.

\section{ACP Conversations Should Include Eliciting Patient Preferences Regarding Care in the Context of Becoming Seriously Ill with COVID-19}

This will require education for patients, surrogate decision makers, and clinicians. Education on the 
possible courses and outcomes of COVID-19 illness can help patients and surrogate decision makers with ACP and making decisions in the case of a diagnosis. People who are older or have chronic medical problems, such as cardiac or lung disease, are at elevated risk for critical illness and death. ${ }^{12,13}$ There is high mortality among patients who become critically ill with COVID-19, and they commonly decline quickly, have long intensive care unit (ICU) stays and prolonged invasive mechanical ventilation (median duration 27 days for survivors in one prospective cohort study), and are placed in the prone position. ${ }^{12}$ One of the men in his 20 s critically ill with COVID-19 without prior medical problems did not survive, and the other man with chronic medical problems survived after a long ICU stay.

Disproportionate rates of critical illness and death among African Americans, Hispanics, Native and Indigenous people, and Native Hawaiian/ Pacific Islanders have brought to the forefront existing health inequities that result from systemic racism. $^{12-15}$.

It is important that clinicians approach discussing patient preferences with cultural and narrative humility, maintaining awareness of their own roles, expectations, and responsibilities in a patient's story. ${ }^{16}$ This culturally sensitive approach should also include respectfully assessing communication and decision-making preferences and addressing cultural, social, and spiritual needs. When completing ACP documents, we recommend use of culturally appropriate advance directives in a patient's preferred language whenever possible.

\section{ACP Resources with COVID-19-Specific Content Can Facilitate Eliciting Patient Preferences}

Reported barriers to having ACP conversations include clinician reluctance, lack of clinician education and resources, and heightened emotion associated with these conversations., ${ }^{2,5,9}$ Clinician and patient experience and comfort with ACP conversations vary. The following language may be helpful for patients who are young and healthy or who may be reluctant to engage in ACP:

1. Who would you want to make decisions for you if something unexpected happened to you like you were in a serious car accident?

2. Have you ever talked to that person about what kind of care you would or would not want? For example, many people would not want to be hooked up to machines long term.
3. Most people who become very ill with COVID-19 are older, but there have been some young adults who have become very ill. I think we should talk about what might happen if at some point you become seriously ill with COVID-19.

Here is suggested language for discussing code status with an older adult with life-limiting chronic medical problems with a diagnosis or pending results for a diagnostic test for COVID-19:

Because of your overall bealth, if you become even sicker and began to die, you would be unlikely to survive $C P R{ }^{1}$

If a trial of intubation is desired:

Older adults with medical issues are unlikely to survive serious COVID-19 infection. I recommend that in the event your condition does not improve after a trial of intubation and intensive care, we shift your care to a comfort-focused approach. ${ }^{1}$

Additional COVID-19-specific resources for $\mathrm{ACP}$ and decision aids are shown in Table 1.

\section{Changes in Billing for ACP and Telehealth Visits Before and during the Pandemic May Facilitate ACP Conversations}

ACP conversations ideally involve patients and family members sharing their stories and concerns during multiple visits. Many clinicians have incorporated ACP conversations into Medicare wellness visits and have electronic medical record (EMR) prompts for this. In addition, in 2016 the Centers for Medicare and Medicaid Services allowed for an add-on billing code for ACP, though estimates suggest this is underused. ${ }^{3,7,8}$

COVID-19 has catapulted telehealth into daily practice for many clinicians. ${ }^{22}$ Many patients find Telehealth visits acceptable, and in some situations preferable. $^{23,24}$ Telehealth and telephone visits, now more easily billable, enable patients to follow up on ACP conversations without having to return to the office. Incorporating ACP conversations into telehealth and telephone visits and dividing up these visits among members of a multidisciplinary team may help overcome the identified barrier of insufficient time during patient visits to complete ACP. ${ }^{6}$ A multidisciplinary approach to ACP conversations offers unique perspectives of clinicians of different disciplines, such as physicians, advance practice providers, nurses, and social workers. Telehealth also facilitates health care surrogate decision makers joining the conversation if they are physically distancing during 
Table 1. COVID-19-Specific Advance Care Planning Conversation Resources

\begin{tabular}{|c|c|c|}
\hline Having the conversation & Suggested phrasing & Resource and description \\
\hline Setting the context & $\begin{array}{l}\text { "We help individuals and their healthcare } \\
\text { agents/families talk about and plan for } \\
\text { their care, before a medical crisis occurs. } \\
\text { We want to know your values and } \\
\text { preferences which will help us understand } \\
\text { what matters most to you should you } \\
\text { become ill due to complications of } \\
\text { COVID-19."17 }\end{array}$ & $\begin{array}{l}\text { Respecting Choices } \\
\text { https://respectingchoices.org/covid-19- } \\
\text { resources/ } \\
\text { Information for clinicians and patients on } \\
\text { advance care planning conversations and } \\
\text { a decision aid for discussing CPR. }\end{array}$ \\
\hline Choosing a surrogate decision maker & $\begin{array}{l}\text { "You are right to be concerned [about } \\
\text { the coronavirus]. Here's what you can } \\
\text { do. Please limit your contact with others } \\
\text {-we call it social distancing. Then you } \\
\text { should pick a person who knows you } \\
\text { well enough to talk to doctors for you } \\
\text { if you did get really sick. That person is } \\
\text { your proxy." } 18\end{array}$ & $\begin{array}{l}\text { VITALtalk } \\
\text { https://www.vitaltalk.org/guides/covid-19- } \\
\text { communication-skills/ } \\
\text { PDFs available in multiple languages. } \\
\text { Website and app (Apple or Android) with } \\
\text { communication frameworks for goals of } \\
\text { care and other often challenging } \\
\text { conversations. }\end{array}$ \\
\hline Previous experience with illness & $\begin{array}{l}\text { "Have you ever had your own experience } \\
\text { with serious illness or a friend or family } \\
\text { member who was very sick or dying? } \\
\text { When you think back, what do you think } \\
\text { went well and what did not go well?"19 }\end{array}$ & $\begin{array}{l}\text { Center to Advance Palliative Care } \\
\text { https://www.capc.org/toolkits/covid-19- } \\
\text { response-resources/ } \\
\text { COVID-19 response resources publicly } \\
\text { available. Other resources available with } \\
\text { membership, continuing medical } \\
\text { education credit available. }\end{array}$ \\
\hline Code status & $\begin{array}{l}\text { "Some people, especially those who are } \\
\text { young and healthy, will get better with } \\
\text { routine hospital care. But many, } \\
\text { especially those who are older and sicker, } \\
\text { are not likely to survive even with a } \\
\text { ventilator (breathing machine)."20 }\end{array}$ & $\begin{array}{l}\text { Ariadne Labs } \\
\text { The Conversation Project } \\
\text { https://theconversationproject.org/covid19/ } \\
\text { Includes the guide for patients "Being } \\
\text { Prepared in the Time of COVID," } \\
\text { available in English and Spanish. }\end{array}$ \\
\hline Further exploring values & $\begin{array}{l}\text { "People may feel very different about this } \\
\text { now in their current health and in the } \\
\text { future if they were to get very sick, such } \\
\text { as if they were to get Coronavirus. Have } \\
\text { you thought about this?"21 }\end{array}$ & $\begin{array}{l}\text { PREPARE for your care (University of } \\
\text { California, San Francisco) also has free } \\
\text { online guides in English and Spanish to } \\
\text { help patients make a medical plan during } \\
\text { COVID-19. }\end{array}$ \\
\hline
\end{tabular}

the pandemic, do not live locally, or have a busy schedule. Telehealth visits are not a solution for every patient, including our most vulnerable patients who do not have reliable access to the Internet, smartphones, or tablets.

\section{COVID-19 Brings New Barriers to Documenting and Accessing ACP Documents, while Old Barriers Persist}

One study found the most frequent outcome of an $\mathrm{ACP}$ intervention was that ACP conversations were initiated but no ACP forms (eg, advance directive or DPOA-HC) were completed. ${ }^{6}$ This outcome may be even more common now due to changes in patient care during the pandemic for patients with and without a diagnosis of COVID-19, including fewer primary care visits. ${ }^{25}$ Telehealth visits may be part of the solution, but other interventions are needed.

Once someone is hospitalized with COVID-19, like the patient cases described, the need for extensive personal protective equipment, minimizing exposures, and visitor restriction policies are challenges to having and documenting ACP conversations with patients and their surrogate decision makers. This not only makes completion of ACP documents technically difficult but can also create a sense of lack of humanity by emotionally distancing the clinician and the family and other loved ones from the patient.

State laws and institutional policies that complicate completion of ACP forms and lack of centralized and consistent location in EMRs for ACP information are significant barriers to completing and accessing ACP. ${ }^{2,4}$ There are efforts being made by EMR vendors, health care systems, states, and clinicians to enable easier ACP documentation and access to documented conversations and completed forms. ${ }^{4}$ Clinicians successfully advocated for an "Advance Directives" tab in our inpatient EMR for ACP forms and code status conversations to more easily retrieve these documents. In addition, during the COVID-19 pandemic our institution allowed 
completion of some ACP forms electronically or via fax, rather than requiring an additional in-person visit.

A larger challenge is access to ACP documents across care settings. Patients may receive primary care or specialty outpatient care and be hospitalized in different health care institutions, all with different EMRs. This complicates access to patients' medical records, including ACP documents.

One temporary fix to the challenge of accessing ACP documents across care settings is to encourage patients and their surrogate decision makers to keep paper and electronic copies of the documents so they are available to be scanned into the EMR when presenting to a new care setting. A more long-term solution to this problem is significantly more challenging and involves institutions, health systems, and federal, state, and local governments working together to facilitate the flow of information across care settings without compromising patient privacy.

\section{Conclusion}

The shared risk for COVID-19 that all people face brings urgency to ACP conversations that include eliciting patient preferences regarding care in the context of becoming critically ill with COVID-19. The pandemic has expedited changes that may facilitate ACP completion, including improved access and ability to bill for telehealth and telephone visits, and institutional policy changes to ACP form completion. However, research should assess acceptability and effectiveness of these strategies.

Authors would like to thank Rashmi K. Sharma, MD, MHS.

To see this article online, please go to: http://jabfm.org/content/ 34/Supplement/S16.full.

\section{References}

1. Jacobsen JC, Tran KM, Jackson VA, Rubin EB. Case 19-2020: A 74-year-old man with acute respiratory failure and unclear goals of care. N Engl J Med 2020;382:2450-7.

2. Jimenez G, Tan WS, Virk AK, Low CK, Car J, Ho AHY. Overview of systematic reviews of advance care planning: summary of evidence and global lessons. J Pain Symptom Manage 2018;56:436-59.e25.

3. Fulmer T, Escobedo M, Berman A, Koren MJ, Hernández S, Hult A. Physicians' views on advance care planning and end-of-life care conversations. J Am Geriatr Soc 2018;66:1201-5.
4. Lamas D, Panariello N, Henrich N, et al. Advance care planning documentation in electronic health records: current challenges and recommendations for change. J Palliat Med 2018;21:522-8.

5. Lund S, Richardson A, May C. Barriers to advance care planning at the end of life: an explanatory systematic review of implementation studies. PLoS One 2015;10:e0116629.

6. Luu NP, Nigrin C, Peairs $\mathrm{K}$, et al. Increasing advance care planning completion at an academic internal medicine outpatient clinic. J Pain Symptom Manage 2017;54:383-6.

7. Tsai G, Taylor DH. Advance care planning in Medicare: an early look at the impact of new reimbursement on billing and clinical practice. BMJ Support Palliat Care 2018;8:49-52.

8. Pelland K, Morphis B, Harris D, Gardner R. Assessment of first-year use of Medicare's advance care planning billing codes. JAMA Intern Med 2019;179:827-9.

9. Izumi S, Fromme EK. A model to promote clinicians' understanding of the continuum of advance care planning. J Palliat Med 2017;20:220-1.

10. Sudore RL, Lum HD, You JJ, et al. Defining advance care planning for adults: a consensus definition from a multidisciplinary Delphi panel. J Pain Symptom Manage 2017;53:821-32.e1.

11. Kim P, Daly JM, Berry-Stoelzle MA, et al. Prognostic indices for advance care planning in primary care: a scoping review. J Am Board Fam Med 2020;33:322-38.

12. Cummings MJ, Baldwin MR, Abrams D, et al. Epidemiology, clinical course, and outcomes of critically ill adults with COVID-19 in New York City: a prospective cohort study. Lancet 2020;395:1763-70.

13. Bhatraju PK, Ghassemieh BJ, Nichols M, et al. Covid19 in critically ill patients in the Seattle region-case series. N Engl J Med 2020;382:2012-22.

14. Kamb L. King County has big racial disparities in coronavirus cases and deaths, according to publichealth data. Seattle Times, May 1, 2020. Available from: https://www.seattletimes.com/seattle-news/ health/king-county-has-big-racial-disparities-incoronavirus-cases-and-deaths-according-to-publichealth-data/.

15. Williams DR, Cooper LA. COVID-19 and health equity-a new kind of "herd immunity." JAMA 2020;323:2478.

16. Tsevat RK, Sinha AA, Gutierrez KJ, DasGupta S. Bringing home the health humanities: narrative humility, structural competency, and engaged pedagogy. Acad Med 2015;90:1462-5.

17. COVID-19 resources. 2020. Available from: https: //respectingchoices.org/covid-19-resources/.

18. COVID ready communication playbook. 2020. Available from: https://www.vitaltalk.org/guides/covid19-communication-skills/. 
19. COVID-19 response resources hub. 2020. Available from: https://www.capc.org/toolkits/covid-19-responseresources/.

20. The Conversation Project. 2020. Available from: https://theconversationproject.org/covid19/.

21. PREPARE for your care. 2020. Available from: https://prepareforyourcare.org/covid-19\#!\#providers.

22. Keesara S, Jonas A, Schulman K. Covid-19 and health care's digital revolution. N Engl J Med 2020;382:e82.

23. Martinez KA, Rood M, Jhangiani N, et al. Patterns of use and correlates of patient satisfaction with a large nationwide direct to consumer telemedicine service. J Gen Intern Med 2018;33:1768-73.

24. Slightam C, Gregory AJ, Hu J, et al. Patient perceptions of video visits using Veterans Affairs telehealth tablets: survey study. J Med Internet Res 2020;22:e15682.

25. Basu S, Phillips RS, Phillips R, Peterson LE, Landon BE. Primary care practice finances in the United States amid the COVID-19 pandemic. Health Aff (Millwood) 2020;39. Available from: https://www. healthaffairs.org/doi/10.1377/hlthaff.2020.00794. 